\title{
ВЗАИМОДЕЙСТВИЕ ЧАСТНЫХ И ПУБЛИЧНЫХ ПРАВОВЫХ СРЕДСТВ В МЕХАНИЗМЕ ПРЕДУПРЕЖДЕНИЯ КРИМИНАЛИЗАЦИИ РЫНКА РИТУАЛЬНЫХ УСЛУГ: СОЦИАЛЬНО-ПРЕДПРИНИМАТЕЛЬСКИЙ АСПЕКТ
}

\author{
Барков А.В., Грачев Р.Ю.
}

Аннотация: В настоящей статье обращается внимание на углубление криминализации российского рынка ритуальных услуг. В качестве одного из основных путей предотвращения криминализации рынка предлагается оптимизация частных и публичных правовых средств в механизме его регламентации. Обосновывается, что особенности данного механизма должны найти отражение в российском законодательстве о погребении и похоронном деле. В следующей части статьи исследуются тенденции и перспективы развития российского законодательства в данной сфере. Выявляя достоинства и недостатки двух активно обсуждаемых в России законопроектов: "О внесении изменений и дополнений в Федеральный закон «О погребении и похоронном деле»», подготовленным Федеральной антимонопольной службой и похоронным сообществом (ориентированным на саморегулирование похоронной отрасли), u «O похоронном деле», опубликованным Минстроем осенью 2014 г. (нацеленным на доминирование лицензионного порядка регулирования рынка ритуальных услуг), авторы делают вывод о необходимости сочетания достоинств двух моделей: саморегулирования и лицензирования Метод или методология исследования: В прочессе работы использовались общенаучные и частно-научные методы познания: диалектический, формально-логический, моделирование и структурно-функииональный. В качестве перспективного направления совершенствования законодательства о погребении и похоронном деле обосновывается возможность использования идеологии сочиального предпринимательства, получивщего в развитых правопорядках практическое применение, которое, на взгляд авторов, позволит оптимизировать частные и публичные правовые средства в механизме регламентачии рынка ритуальных услуг. Ключевые слова: Похоронное дело, рынок ритуальных услуг, лицензирование, саморегулирование, соииальное предпринимательство, криминализация, бесконтрольность, услуга, государственный контроль, лицензия.

На активную криминализацию похоронноритуальной сферы и необходимость противодействия этому процессу в целях совершенствования механизма правого регулирования рынка ритуальных услуг неоднократно обращалось внимание в средствах массовой информации [1]. Вместе с тем, несмотря на прилагаемые усилия, криминальная ситуация в данной сфере в ряде регионов России только ухудшается. По оценке Российского информационного агентства «Ура.Ру», в Свердловской области на рынке ритуальных услуг «ситуация ухудшилась катастрофически» [2], так как услуги по организации погребения нередко предоставляют полукриминальные элементы с соответствующими методами работы. Российское информационное агентство «Ура.Ру» сообщает, что «в битве 
за «клиента» черные похоронщики устраивают настоящие облавы друг на друга. «Вес» взятки за информацию об адресах покойников за три года увеличился в 10 раз, объем незаконных платежей оценивается в десятки миллионов рублей» [3].

По мнению экспертов, неблагоприятная ситуация на рынке ритуальных услуг сложилась в результате бесконтрольности со стороны государства. В связи с этим ответственность за контроль всего рынка в апреле 2014 г. была возложена на Министерство строительства и жилищно-коммунального хозяйства (далее: Минстрой). Премьер-министр Д. Медведев в официальном документе по передаче Минстрою данной сферы указал причину такого шага: «В связи с криминализацией отрасли» [4].

В качестве первоочередной задачи реформирования похоронной отрасли в целях снижения уровня ее криминализации Минстрой определился в необходимости совершенствования нормативно-правовой базы рынка ритуально-похоронных услуг, основу которой составляет не отвечающий современным реалиям Федеральный закон от 12.01.1996 г. № 8-Ф3 «О погребении и похоронном деле» [5]. О его несовершенстве на протяжении последних пятнадцати лет говорилось неоднократно при обсуждении различных вариантов его реформирования. Несовершенство закона связывалось в основном с тем, что в переходный период от административно-командной к рыночной экономике по инерции пытались использовать потенциал советской правовой модели. Поэтому неслучайно размещение Минстроем на своем официальном сайте в октябре 2014 г. проекта Ф3 «О похоронном деле» [6] для общественного обсуждения вызвало очередную активную дискуссию о тенденциях и перспективах развития правового обеспечения похоронной отрасли.

Эффективность правового регулирования рыночных отношений в похоронной сфере зависит от нахождения оптимального баланса публичных, общественных и частных интересов[7]. В связи с этим, на наш взгляд, в качестве противодействия криминализации рынка похоронных услуг следует рассматривать поиск баланса частных и публичных правовых средств регламентации рыночных отношений, на особенностях которых остановимся подробнее.

Отмечается, что в настоящее время в мировой практике наиболее успешно используются две модели (формы) государственного контроля и регулятивного воздействия на отдельные отрасли хозяйствования: выдача разрешений (лицензий) на осуществление отдельных видов работ, оказание услуг, распространение товаров и саморегулирование. Обращая внимание на эволюцию моделей государственного правового воздействия на похоронную отрасль, следует отметить, что до 1996 г. доминировала первая. Лицензированию подлежала деятельность по оказанию следующих видов ритуальных услуг: прием заказа и заключение договора на организацию похорон; бальзамирование; санитарная и косметическая обработка трупов; захоронение и перезахоронение; услуги крематориев; уход за могилой; изготовление гробов; заключение прижизненного договора на оказание ритуальных услуг[8]. Затем в соответствии с Федеральным законом от 8 августа 2001 г. № 128 «О лицензировании отдельных видов деятельности» [9] лицензирование этой сферы было отменено.

С этого момента начинает более четко прослеживаться динамика перехода ко второй модели (форме) регулирования, коей является деятельность специализированных институтов профессионального общественного воздействия, созданию и развитию которых способствует государство. Указанные институты приобрели в России вид некоммерческих саморегулируемых организаций (СРО), каждой из которых соответствует определенный вид предпринимательской деятельности, ведомый ее членами. Следует особо подчеркнуть, что и тот, и другой механизмы имеют широкое распространение не только в нашей стране, но и в системах права абсолютного большинства зарубежных стран[10].

С вектором на саморегулирование связывалось реформирование законодательства о похоронном деле, инициатором которого выступала Федеральная антимонопольная служба и наиболее крупные саморегулируемые организации в данной сфере[11]. Среди мер, направленных на демонополизацию рынка похоронных услуг, предполагались: создание саморегулируемой организации в сфере ритуальных услуг, устанавливающей требования к своим членам, к качеству услуг, правила похоронной этики, а также механизм компенсации ущерба, причиненного потребителям услуг - из компенсационного фонда СРО; установление прозрачности цен на ритуальные услуги путем введения требования о размещении в открытом доступе, в том числе на зданиях администраций кладбищ, на сайтах местных администраций и сайтах администраций кладбищ, в местных СМИ сведений о членах СРО и ценах на ритуальные услуги, и т.д.

Отмеченная нами выше тенденция к постепенной отмене лицензирования в отношении многих видов деятельности как процесс либерализации 
экономической деятельности в целом в научной литературе рассматривалась положительно. Вместе с тем применительно к сфере оказания ритуальных услуг вставал вопрос «об адекватной замене лицензирования иными мерами, в частности, техническим регулированием» [12], в целом присущим и другим отмененным рассматриваемым законом ранее лицензируемым видам деятельности. Действительно, в соответствии с Законом РФ «О техническом регулировании» на изделие, объекты, процессы, предоставляющие потенциальную опасность для жизни и здоровья людей, имущества физических и юридических лиц, окружающей среды должны разрабатываться технические регламенты. Такие регламенты должны были заменить нормативные и директивные документы, в которых в настоящее время содержатся обязательные требования по безопасности изделий, объектов, процессов, в том числе документы: ГОСТ и ГОСТ Р, СНиПы, СанПиНы, рекомендации. Вместе с тем отмечалось, что применительно к ритуально-похоронной сфере следовало разработать технический регламент «Безопасность объектов, изделий, материалов, оборудования ритуально-похоронного назначения». Этот регламент, по мнению Р.Г. Набиева, должен был быть принят в качестве федерального закона. Предполагалось, что в него должны войти нормы действующих санитарных норм и правил СанПиН 2.1.1279-03 «Гигиенические требования к размещению, устройству и содержанию кладбищ, зданий и сооружений похоронного назначения». В регламенте, в частности, должны были быть установлены требования по безопасности к гробам, которые предназначены для использования при кремации тел умерших. Такая постановка вопроса Р.Г. Набиевым представляется вполне логичной[13]. Однако, несмотря на то, что данное предложение было высказано в 2007 г., реализация его несколько запоздала. Лишь с 1 января 2013 г. легализован ГОСТ Р 54611-2011 - «Услуги по организации и проведению похорон», что, несомненно, положительно скажется на качестве ритуально-похоронных услуг[14].

В законопроекте, подготовленном Минстроем, в противовес законопроекту, подготовленному ФАС, предполагается в качестве основной новеллы возрождение института лицензирования в отношении таких услуг, как прием заказа, заключение договора на организацию похорон и сопровождение похорон; подготовка и проведение обряда прощания; захоронение, эксгумация и перезахоронение останков и др. Согласно проекту закона, предла- гается установить ответственность должностных и юридических лиц за правонарушения в сфере похоронного дела путем внесения соответствующих изменений в Кодекс РФ об административных правонарушениях. Например, сотрудников медучреждений и полиции смогут привлечь к административной ответственности за незаконную передачу данных о смерти лиц ритуальным агентствам. По информации министра строительства и жилищнокоммунального хозяйства Российской Федерации М.А. Меня[15], принятие данного закона планировалось в Госдуме осенью 2014 года. Следовательно, можно сделать вывод, что в настоящее время российский законодатель отдает приоритет модели государственного воздействия на похоронную отрасль, ориентированной на лицензирование, что, безусловно, оправданно в условиях высокой степени ее криминализации.

Ранее нами отмечалось, что регулятивное воздействие и контроль через механизмы лицензирования не только не является изжившим себя способом защиты государством публичных интересов, но, напротив, может и должен продолжать применяться в отдельных отраслях экономики и даже охватывать собой некоторые виды деятельности, осуществление которых ныне не требует специальных разрешений. Его главным преимуществом является возможность государства как главного выразителя публичного интереса поддерживать баланс между потребностями общества и отдельных лиц, осуществляющих экономическую деятельность.

В этом контексте вызывает некоторое беспокойство деятельность отдельных министерств и ведомств, а также Федерального Собрания, направленная на создание системы регулирования социально и экономически значимых видов деятельности, за малым изъятием исключающей разрешительные процедуры. Полный отказ от модели правового регулирования и контроля представляется ошибочным, так как разрешительный метод имеет немало преимуществ по отношению к саморегулированию[16]. Наряду с разработкой технических регламентов положительно оцениваем стремление легально возвратить процедуру лицензирования оказания ритуальных услуг, практика которого имеется во многих странах мира, что, на наш взгляд, благотворно скажется на защите прав потребителей.

Как справедливо отмечает Р.3. Лившиц, «в природе рынка социальная защищенность человека просто не заложена. Чтобы обеспечить подобную защищенность, ее нужно ввести извне. В этом одно 
из важнейших направлений деятельности государства и права как средства сохранения стабильности общества. Вот почему государственно-правовое вмешательство в экономику необходимо, ибо оно несет в себе социальную защищенность человека. Мера вмешательства государства и права, формы вмешательства здесь различны, они зависят от состояния общества» [17]. В связи с этим, на наш взгляд, с учетом реалий незавершенного этапа перехода к рыночной экономике представляется необходимым гармоничное и взвешенное сочетание достоинств двух моделей: лицензирования и саморегулирования.

В наиболее общем виде саморегулирование можно определить как деятельность некоммерческих организаций, специально созданных для защиты прав неограниченного круга лиц, обладающих контрольными и распорядительными функциями, свойственными органам государственной власти[18]. Саморегулирование с точки зрения многих специалистов является «одним из признаков цивилизованности отношений между государством и бизнесом» [19]. При этом его развитие может и по-прежнему должно рассматриваться как одно из приоритетных направлений в совершенствовании качества регулирования в России[20]. Данный способ организации регулирования и контроля отдельных видов деятельности имеет достаточно длительную историю в развитых странах и используется зачастую параллельно с лицензированием. Для отечественной же системы права саморегулирование является новой правовой конструкцией[21].

Как и лицензирование, саморегулирование имеет целый ряд положительных свойств. К ним, в частности, можно отнести частичную самостоятельность организации отраслевой деятельности лицами, участвующими в ней, что, безусловно, способствует повышению ее эффективности. Таким образом, непосредственные участники правоотношений в рамках отдельных видов деятельности получают возможность влиять на отраслевое регулирование, а не просто быть пассивными исполнителями государственной воли. Кроме того, субъекты саморегулируемой деятельности получают доступ к «форуму», в рамках которого они имеют возможность напрямую выразить свое мнение в отношении тех или иных аспектов государственного регулирования выполняемых ими работ, оказываемых услуг, реализации ими определенных видов товаров. Думается, что легализация необходимости приобретения статуса саморегулируемой организации отсечет от рынка ритуальных услуг недобросовестных криминализированных «черных» похоронных агентств, не способных пройти корпоративную сертификацию, и послужит репутационной гарантией для организации, пожелавшей приобрести обязательную лицензию.

Таким образом, логика развития законодательства о похоронном деле и ритуальном обслуживании состоит на настоящем этапе в том, чтобы выработать и закрепить в виде нормативно установленных правил систему «сорегулирования», опирающуюся, с одной стороны, на саморегулируемую структуру профессионального сообщества, а с другой, на федеральный орган исполнительной власти в лице министерства строительства и жилищно-коммунального хозяйства Российской Федерации, что, на наш взгляд, обеспечит оптимальное взаимодействие частных и публичных правовых средств в механизме воздействия на рынок ритуально-похоронных услуг. Представляется, что в этом направлении и должно проходить последующее обсуждение проекта Ф3 «О похоронном деле».

Говоря о перспективах развития законодательства о погребении и похоронном деле, на наш взгляд, в качестве оптимального направления его совершенствования предлагается с учетом опыта развитых правопорядков использование правовой модели социального предпринимательства. Термины «социальное предпринимательство» (social entrepreneurship) в англо-американской традиции и «социальный предприниматель» (social entrepreneur) - в европейской вошли в научный оборот впервые сравнительно недавно, лишь в 60-е годы XX века. Суть социального предпринимательства наиболее четко выражена Биллом Дрейтоном, основателем компании «Ашока»: «Социальные предприниматели не довольствуются тем, чтобы просто дать человеку рыбы, или обучить, как ее ловить. Они не успокоятся до тех пор, пока не революционизируют саму рыбную отрасль» [22]. По мнению Грегори Диза (директора центра развития социального предпринимательства Университета Дюка США), «наше время созрело для того, чтобы решать социальные проблемы «предпринимательскими» средствами» [23] .В литературе под социальным предпринимательством понимается предпринимательская деятельность, нацеленная на смягчение или решение социальных проблем, характеризующаяся следующими признаками: социальное воздействие; инновационность; самоокупаемость и финансовая устойчивость; масштабируемость и тиражируемость; предпринимательский подход[24]. Данное явление занимает особое место 
в обществе и, находясь на стыке предпринимательства и благотворительности, впитывает в себя их положительные черты: от благотворительности - социальную направленность деятельности, от бизнеса - предпринимательские принципы, что позволяет социальному предпринимательству генерировать новый подход к решению социальных задач. Сегодня социальное предпринимательство переживает новый исторический этап развития, связанный с тем, что во многих современных правопорядках оно рассматривается как продолжение государственной социальной политики, направленное на решение различных проблемных вопросов, от экологических до защиты социально уязвленных слоев общества.

Во многих странах данная идея получила практическое воплощение. Для решения различных социальных проблем общества в 2009 г. в Великобритании сформировано министерство социального предпринимательства, в 2010 г. в Южной Корее при правительстве создано Агентство по продвижению социального предпринимательства, в 2011 г. в США объявлено о формировании «четвертого сектора экономики», на базе которого с использованием инноваций социального предпринимательства будут решаться социальные проблемы.

В зависимости от определения роли и места государства как законодателя в организации решения социальных проблем выделяется две модели социального предпринимательства: американская и европейская[25]. В США большая часть внешнего финансирования получается от частных фондов. Особенность американского пути развития социального предпринимательства заключается в том, что в США существует достаточно разветвленная и устойчивая сеть частной поддержки в виде благотворительных фондов. В Европе роль государства в определении стратегии развития правовой политики социального предпринимательства огромна, так как основана на государственной поддержке органами государственной власти и Европейским союзом. Несмотря на некоторые различия в подходах к правовой регламентации социального предпринимательства и деятельности социальных предприятий Америки и Европы, общее, что объединяет их, - это стремление оказать поддержку социальному предпринимательству, рассматриваемому как обновленное направление государственной социальной политики[26]. Направлением совершенствования законодательства является правовое обеспечение межсекторного взаимодействия.

Вместе с тем, несмотря на заметный интерес к зарубежному опыту социального предприни- мательства на самом высоком уровне, в России наблюдается тенденция отождествления социального предпринимательства с «предпринимательской деятельностью, осуществляемой с целью оказания социальных услуг» [27], что не вполне соответствует мировой практике. Как известно, по итогам встречи с предпринимателями в социальной сфере Председателем Правительства дано поручение по разработке дефиниции «предпринимательской деятельности, осуществляемой в целях оказания социальных услуг», а не «социального предпринимательства», о котором шла речь на встрече, что, очевидно, не одно и то же. Несмотря на активно обсуждаемые предложения о легализации понятия социального предпринимательства как социально ориентированной предпринимательской деятельности по оказанию социальных услуг[28], даже такая упрощенная дефиниция не получила отображение в Федеральном законе «Об основах социального обслуживания населения в Российской Федерации» [29]. В связи с этим в настоящее время особый интерес представляет выработка критериев социального предприятия, что обусловливает необходимость изучения передового зарубежного опыта.

В Великобритании Кабинет министров поставил задачу финансирования развития и поддержки социального предпринимательства, и Казначейство Великобритании (Министерство финансов) дало следующее легальное определение социальных предприятий. «Социальные предприятия являются частью «третьего сектора», охватывающей все неправительственные организации, которые принципиально реинвестируют прибыль в сообщество или организацию и стремятся к достижениям в общественной жизни и в защите окружающей среды, и не используют ее для максимизации доходов совладельцев или собственника предприятия. Третий сектор охватывает добровольные и общественные организации, благотворительные учреждения, социальные предприятия, общества взаимопомощи и кооперативы» [30]. Данное определение конкретизируется с учетом ряда пространных, не вполне четких экономических и социальных критериев[31].

В Южной Корее, обобщившей британский опыт, критерии социального предприятия более конкретны. В Законе о развитии социального предпринимательства, принятом 7 января 2007 г., в соответствии со ст. 2 термин «социальное предприятие» распространяется на организации, занимающиеся деятельностью по производству и продаже товаров и услуг и преследующие социальные цели 
повышения качества жизни местных жителей путем оказания социальных услуг и создания рабочих мест для незащищенных слоев населения при условии, что данные предприятия прошли процедуру сертификации, предусмотренную ст. 7 Закона[32]. Данное определение конкретизируется в Постановлении о реализации Закона о развитии социального предпринимательства, утвержденном в июле 2007 г. указом президента Кореи. Социальным признается предприятие в случаях:

1) если основной целью деятельности организации является трудоустройство незащищенных лиц. При этом доля занятых незащищенных лиц среди работников предприятия должна составлять не менее 50\% (до июля 2011 - не менее 30\%);

2) если основной целью деятельности организации является предоставление социальных услуг в соответствии с п. 3 ст. 2 Постановления. При этом доля незащищенных лиц среди всех лиц, которым оказаны услуги, должна составлять не менее 50\% (до июля 2011 г. - 30\%);

3) если основной целью деятельности организации является одновременно и трудоустройство незащищенных лиц, и предоставление им социальных услуг. При этом доля трудоустроенных незащищенных лиц среди всех работников предприятия и доля незащищенных лиц среди всех лиц, которым оказаны услуги, должны составлять не менее 30\% (до июля 2011 г. - 20\%).

В тех случаях, когда появляются трудности в определении того, реализуются ли социальные задачи в соответствии с требованиями закона, решение о присвоении статуса социального предприятия принимается Министерством труда после рассмотрения данного вопроса Комитетом по поддержке[33]. В ст. 2 Постановления подробно перечисляются категории граждан, имеющих право на приобретение статуса «незащищенные слои населения». Ст. 3 Постановления дает определение критерия «социальные услуги». При этом Министерство труда вправе присвоить статус «социальная услуга» в индивидуальном порядке в том случае, если социально значимая деятельность не соответствует легальным критериям.

Представляется, что идеология социального предпринимательства применима и для совершенствования законодательства в сфере похоронного дела, где в связи с высокой социальной значимостью отрасли получение прибыли не должно стать доминирующим. Так, например, данный подход успешно реализуется в настоящее время в Финляндии, где социальные предприятия похоронной отрасли работают на самоокупаемости, не думая ни о какой прибыли в данной деликатной сфере[34]. В связи с этим представляется целесообразным по аналогии с британским социальным предприятием - компанией общественного интереса и ее южнокорейским аналогом закрепить за специализированной службой по вопросам похоронного дела необходимость реинвестирования 2/3 прибыли в развитие социальной сферы - похоронного дела, что положительно скажется на оптимизации цены и качества ритуальных услуг и значительно снизит уровень криминализации похоронной сферы.

\section{Библиография:}

1. HM Treasury, DTI, Home Office UK Exploring the Role of the Third Sector in Public Service Reform (February 2005) // Портал кооперативного движения Великобритании Co-operatives.uk. URL: http:// www.uk.coop/sites/storage/public/downloads/se_action_plan_2006_0.pdf (дата обращения 02.08.2014).

2. Social Enterprise // Энциклопедический сайт Великобританий URL: http://en.wikiversity.org/wiki/ Social_Enterprise (дата обращения 12.12.2014).

3. Барков А.В. Рынок социальных услуг: проблемы правого регулирования : дис. ... докт. юрид. наук. М., 2008. 625 c.

4. Дементьева Е. Похоронная отрасль в Финляндии глазами российских специалистов // С уважением к памяти. 2014. № 8 (72). URL: http://funeralassociation.ru/ru/newspaper/archives/7214/7202/ (дата обращения: 11.01.2015).

5. Законопроект о похоронном деле рассмотрят в Госдуме осенью - глава Минстроя // PAПCИ. URL: http://rapsinews.ru/legislation_news/20140908/272073559.html\#ixzz3I0aKfAzW (дата обращения 03.11.2014).

6. Киселева О. Саморегулируемый бизнес // Политический журнал. 2004. 7 сентября. URL: http://www. valuer.ru/files/ds/inf_070904.htm (дата обращения: 7.01.2012).

7. Крючкова П. О саморегулируемых организациях: эксп. ком. к законопроекту // На полпути к саморегулированию. URL: http://www.valuer.ru/files/ds/inf_290604.htm (Дата обращения: 7.01.2012). 
8. Кузнецова О.А. Принципы гражданского права: современное состояние вопроса. // Власть закона. 2011. № 4 (8). C. 87-95.

9. Кутепова М. «Вот где ад. За гробовые деньги бьются в кровь» // Российское информационное агентство «Ура.py». URL: http://ura.ru/content/svrd/21-08-2014/articles/1036262776.html (дата обращения 06.01.2015).

10. Лившиц Р.З. Теория права: учебник. М.: Издательство БЕК, 1994. С. 178.

11. Минстрой России подготовил законопроект о похоронном деле // Официальный сайт Министерства строительства и жилищно-коммунального хозяйства Российской Федерации. URL: http://minstroyrf. ru/press/minstroy-rossii-podgotovil-zakonoproekt-o-pokhoronnom-dele/ (дата обращения 03.11.2014).

12. Московский справочник ритуальных услуг: URL: http://www.mos-ritual.ru/zakonodatelstvo/federalnoezakonodatelstvo/gost-r-546112011-uslugi-po-organizatsii-i-provedeniyu-pohoron (дата обращения 23.12.2014).

13. Набиев Р.Г. Возмездное оказания ритуальных услуг в Российской Федерации: дис. ... канд. юрид. наук. Волгоград, 2007. 195 с.

14. О лицензировании отдельных видов деятельности: Федеральный закон от 8 августа 2001 г. № 128 // CПС «Гарант». URL: http://base.garant.ru/12123874/ (дата обращения 03.11.2014).

15. Об основах социального обслуживания населения в Российской Федерации: Федеральный закон от 13 декабря 2013 г. № 442-Ф3 // Российская газета. 2013. 30 декабря.

16. Пилипчук А. Дело похоронной мафии / Информационный портал Право.py. URL: http://pravo.ru/ process/view/30976/ (дата обращения 29.12.2014)

17. Плескачевский В. Саморегулируемые организации. Проблемы развития, законодательства и правоприменительной практики: выступление на парламентских слушаниях в Совете Федерации // На принципах саморегулирования. URL: http://www.valuer.ru/files/ds/inf_160604.htm (Дата обращения: 23.11.2011).

18. Положение о порядке лицензирования деятельности по оказанию ритуальных услуг: утв. постановлением Правительства РФ от 26 декабря 1995 г. № 1272.

19. Поручения по итогам встречи с предпринимателями в социальной сфере // Официальный сайт Правительства РФ. URL:http:/government.ru/orders/7515 (дата обращения 10.07.2014).

20. Пояснительная записка к проекту Федерального закона «О внесении изменений и дополнений в Федеральный закон «О погребении и похоронном деле»»» // URL: regulation.gov.ru>get.php?doc $\mathrm{id}=28599 \& v i e w \_\mathrm{id}=12$ (дата обращения 03.11.2014).

21. Сенаторы предлагают ввести понятие «социальный предприниматель» // Портал «Вместе с Россией». URL: http://vmeste-rf.tv/news/19288.do (дата обращения 10.07.2014).

22. Серова О.А. Признаки саморегулируемых организаций // Вестник Самарской гуманитарной академии. Серия: Право. 2007. № 1. С. 81-85.

23. Собрание законодательства РФ от 15.01.1996, № 3, ст. 146 (с изм. от 04.06.2014).

24. Социа́льное предпринима́тельство // Википедия.

25. Трушин Г. Частные кладбища в России: реальность или утопия? // Проект «Вести. Недвижимость». URL: http://realty.vesti.ru/news/show/id/6721 (дата обращения 11.01.2015).

\section{References (transliterated):}

1. HM Treasury, DTI, Home Office UK Exploring the Role of the Third Sector in Public Service Reform (February 2005) // Portal kooperativnogo dvizheniya Velikobritanii Co-operatives.uk. URL: http://www. uk.coop/sites/storage/public/downloads/se_action_plan_2006_0.pdf (data obrashcheniya 02.08.2014).

2. Social Enterprise // Entsiklopedicheskii sait Velikobritanii URL: http://en.wikiversity.org/wiki/Social_Enterprise (data obrashcheniya 12.12.2014).

3. Barkov A.V. Rynok sotsial'nykh uslug: problemy pravogo regulirovaniya : dis. ... dokt. yurid. nauk. M., 2008. $625 \mathrm{~s}$.

4. Dement'eva E. Pokhoronnaya otrasl' v Finlyandii glazami rossiiskikh spetsialistov // S uvazheniem k pamyati. 2014. № 8 (72). URL: http://funeralassociation.ru/ru/newspaper/archives/7214/7202/ (data obrashcheniya: 11.01.2015). 
5. Zakonoproekt o pokhoronnom dele rassmotryat v Gosdume osen'yu - glava Minstroya // RAPSI. URL: http:// rapsinews.ru/legislation news/20140908/272073559.html\#ixzz3I0aKfAzW (data obrashcheniya 03.11.2014).

6. Kiseleva O. Samoreguliruemyi biznes // Politicheskii zhurnal. 2004. 7 sentyabrya. URL: http://www.valuer. ru/files/ds/inf_070904.htm (data obrashcheniya: 7.01.2012).

7. Kryuchkova $\overline{\mathrm{P}}$. O samoreguliruemykh organizatsiyakh : eksp. kom. k zakonoproektu // Na polputi k samoregulirovaniyu. URL: http://www.valuer.ru/files/ds/inf_290604.htm (Data obrashcheniya: 7.01.2012).

8. Kuznetsova O.A. Printsipy grazhdanskogo prava: sovremennoe sostoyanie voprosa. // Vlast' zakona. 2011. № 4 (8). S. 87-95.

9. Kutepova M. «Vot gde ad. Za grobovye den'gi b'yutsya v krov'» // Rossiiskoe informatsionnoe agentstvo «Ura. ru». URL: http://ura.ru/content/svrd/21-08-2014/articles/1036262776.html (data obrashcheniya 06.01.2015).

10. Livshits R.Z. Teoriya prava : uchebnik. M.: Izdatel'stvo BEK, 1994. S. 178.

11. Minstroi Rossii podgotovil zakonoproekt o pokhoronnom dele // Ofitsial'nyi sait Ministerstva stroitel'stva i zhilishchno-kommunal'nogo khozyaistva Rossiiskoi Federatsii. URL : http://minstroyrf.ru/press/minstroyrossii-podgotovil-zakonoproekt-o-pokhoronnom-dele/ (data obrashcheniya 03.11.2014).

12. Moskovskii spravochnik ritual'nykh uslug: URL: http://www.mos-ritual.ru/zakonodatelstvo/federalnoe-zakonodatelstvo/gost-r-546112011-uslugi-po-organizatsii-i-provedeniyu-pohoron (data obrashcheniya 23.12.2014).

13. Nabiev R.G. Vozmezdnoe okazaniya ritual'nykh uslug v Rossiiskoi Federatsii : dis. ... kand. yurid. nauk. Volgograd, 2007. $195 \mathrm{~s}$.

14. O litsenzirovanii otdel'nykh vidov deyatel'nosti: Federal'nyi zakon ot 8 avgusta 2001 g. № 128 // SPS «Garant». URL: http://base.garant.ru/12123874/ (data obrashcheniya 03.11.2014).

15. Ob osnovakh sotsial'nogo obsluzhivaniya naseleniya v Rossiiskoi Federatsii : Federal'nyi zakon ot 13 dekabrya 2013 g. № 442-FZ // Rossiiskaya gazeta. 2013. 30 dekabrya.

16. Pilipchuk A. Delo pokhoronnoi mafii / Informatsionnyi portal Pravo.ru. URL: http://pravo.ru/process/ view/30976/ (data obrashcheniya 29.12.2014)

17. Pleskachevskii V. Samoreguliruemye organizatsii. Problemy razvitiya, zakonodatel'stva i pravoprimenitel'noi praktiki : vystuplenie na parlamentskikh slushaniyakh v Sovete Federatsii // Na printsipakh samoregulirovaniya. URL: http://www.valuer.ru/files/ds/inf_160604.htm (Data obrashcheniya: 23.11.2011).

18. Polozhenie o poryadke litsenzirovaniya deyatel'nosti po okazaniyu ritual'nykh uslug : utv. postanovleniem Pravitel'stva RF ot 26 dekabrya 1995 g. № 1272.

19. Porucheniya po itogam vstrechi s predprinimatelyami v sotsial'noi sfere // Ofitsial'nyi sait Pravitel'stva RF. URL:http://government.ru/orders/7515 (data obrashcheniya 10.07.2014).

20. Poyasnitel'naya zapiska k proektu Federal'nogo zakona «O vnesenii izmenenii i dopolnenii v Federal'nyi zakon «O pogrebenii i pokhoronnom dele»»" // URL: regulation.gov.ru get.php?doc_id=28599\&view_id=12 (data obrashcheniya 03.11.2014).

21. Senatory predlagayut vvesti ponyatie "sotsial'nyi predprinimatel'» // Portal «Vmeste s Rossiei». URL: http:// vmeste-rf.tv/news/19288.do (data obrashcheniya 10.07.2014).

22. Serova O.A. Priznaki samoreguliruemykh organizatsii // Vestnik Samarskoi gumanitarnoi akademii. Seriya: Pravo. 2007. № 1. S. 81-85.

23. Sobranie zakonodatel'stva RF ot 15.01.1996, № 3, st. 146 (s izm. ot 04.06.2014).

24. Sotsiál'noe predprinimátel'stvo // Vikipediya.

25. Trushin G. Chastnye kladbishcha v Rossii: real'nost' ili utopiya? // Proekt «Vesti. Nedvizhimost'». URL: http://realty.vesti.ru/news/show/id/6721 (data obrashcheniya 11.01.2015). 